\title{
Fault/no fault part 2: uneasy bedfellows
}

\section{Is the patient safety movement on a "collision course" with the medical malpractice system?}

$\mathrm{V}$ ance Davis was just 19 when he died in a Saskatchewan hospital 6 years ago. He had been admitted for a head injury. Vance had a high level of consciousness in the intensive care unit, but that level dropped dramatically in the few minutes it took to transfer him to a ward. The change was recorded, but its significance was neither noted nor acted upon. It was 4 hours before a doctor was called and by then, precious time had been lost.

His mother Donna, a nurse, knew that what had happened in the hospital had likely contributed to his death, and she sought answers.

"I wanted the truth, I wanted it not to happen again to anyone else." She and her husband also would have appreciated an apology.

Instead, when she contacted the hospital with some questions, Davis was told to talk to a lawyer. It was only after threatening legal action that she was able to get her son's chart and computed tomography scan results.

Her experience is not uncommon, primarily because it is the law, to a very large extent, that shapes how health care providers and institutions respond to patients and their families who have suffered harm.

In countries like Canada and the United States, responses have largely been dictated by the tort system, in which patients who have suffered harm must, for the most part, launch lawsuits and prove fault in order to receive compensation. Some observers argue that the system spells trouble for the growing patient safety movement, which aims to reduce errors. Others have gone so far as to say the movement is "on a collision course" with the medical malpractice system (JAMA 2001;286:217-23).

Even the Canadian Patient Safety Institute acknowledged, in a consultation paper released in July 2008, that fear of litigation, together with limited re-

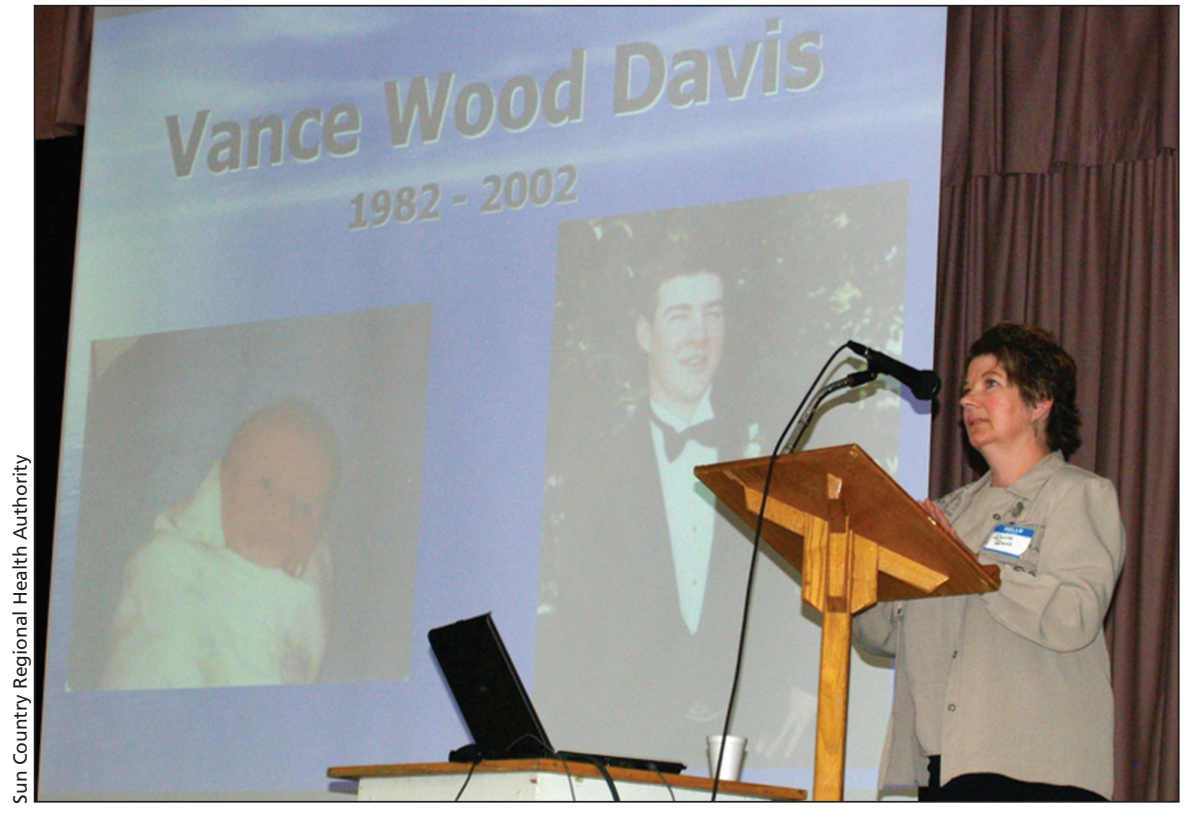

After the death of her son Vance (pictured on slide), nurse Donna Davis became an advocate for providing more information to patients and their families.

sources and fear of disciplinary action, present a "challenge" when it comes to efforts to implement reforms designed to improve reporting about mishaps or enhance learning from mistakes.

The threat of lawsuits does "help put the fear of God into hospitals to be a bit more careful, to do a better job, because no one likes being sued," says James Kreppner, a Toronto lawyer with hemophilia who was infected with HIV through tainted blood and who has worked with the Canadian Hemophilia Society in examining different approaches to compensation for medical miscues. "But it also encourages them to hide medical misadventures, so you will never know they gave you the wrong batch of whatever - it can lead to secrecy when openness would better serve everyone."

The patient safety movement has been gathering steam ever since the 1999 publication of the groundbreaking report To Err is Human: Building a Safer
Health System, by the US Institute of Medicine. A subsequent Canadian study estimated that $7.5 \%$ of patients admitted to hospital in 2000 suffered from 1 or more adverse events, and that for a third of those patients, the adverse events were "highly preventable." The study authors further estimated that between 9250 and 23750 hospital patients died that year from a preventable adverse event (CMAJ 2004;170[11]:1678-86).

To many observers, the rise of the movement provides a fresh rationale to consider implementing no-fault systems of compensation.

Calls for stepped-up adverse event reporting and greater disclosure of errors are integral to patient safety. This means that advocates - concerned about causes and consequences - will have to pay more attention to the needs of injured patients. This includes the need for compensation, says Joan Gilmour, professor at the Osgoode Hall Law School at York University in Toronto, Ontario, who 
studied the interface of patient safety and tort law internationally in a report commissioned by Health Canada (Box 1).

As well, changes in the models of health care delivery - in particular, the movement toward care provided by teams using advanced technologies in increasingly complex arrangements affect issues of liability. The tort system developed at a time when health professionals worked independently or in simpler groups. In legal circles, that made for clear-cut lines of responsibility. But in the new health care delivery arrangements, things aren't quite as straightforward and increasingly, there's widespread acceptance of the notion that underlying systemic problems cause more harm to patients than do the actions of individual health care providers.

That certainly muddies the legal waters, compelling some to argue that simple fairness to patients necessitates a move toward no-fault compensation, because the systemic changes make it even more difficult for them to meet the tort system's onus that they prove fault.

Others point to tort reform to address patient safety issues.

"What I found was that in countries that came to the patient safety sensibility earlier [than Canada], some had also undertaken significant reform in tort law," Gilmour says.

But the main aim of the reform was to reduce the size and risk of legal judgments - not to advance the patient safety agenda — and it had limited impact on disclosure of harm and accident prevention, she adds. Interestingly, Gilmour found that in New Zealand, which since 1974 has had a no-fault compensation system for medical injuries, disclosure of adverse events was not noticeably greater. Indeed, New Zealand experts have concluded that their hospitals "appear no safer" than those in other Western countries. "The unfinished business [of the no-fault system] lies in realizing its full potential for improving patient safety" (Health Affairs 2006;25:278-83).

By contrast, Denmark, another country with a no-fault compensation system, has been aggressive in promoting patient safety and was the first country to set up a national adverse events monitoring system; front-line personnel are obligated to report adverse events. The result has been increased reporting and system improvement.

The Danish Medical Association was instrumental in supporting the monitoring system and the 2003 Act on Patient Safety in the Danish Health Care System. Under the legislation, there is a included qualified privilege laws, which are now in place in various forms in all provinces and territories and which aim to increase openness by shielding certain information, gathered for safety and quality improvement purposes, from disclosure in legal proceedings. The level of protection varies by jurisdiction. For example, in both Ontario and Saskatchewan, "facts" are not shielded.

But the "cost" of such privilege laws is that potentially relevant information is not made available to the public or the individual patient, Gilmour says, citing the example of the Newfoundland Commission of Inquiry into Hormone Receptor Testing, which itself had to obtain a legal ruling in order to gain access to an external evaluator's

\section{Patient safety is "freedom from accidental injury; ensuring patient safety involves the establishment of operational systems and processes that minimize the likelihood of errors and maximize the likelihood of intercepting them when they occur." \\ - To Err is Human: Building a Safer Health Care System, the US Institute of Medicine.}

clear distinction between information gathered for the purposes of complaints and compensation, and information gathered for the monitoring system.

"If a patient's entitlement were linked to fault, it would have been impossible to have the Patient Safety Act, where investigation of adverse events is done in a confidential manner," says Dr. Jepser Paulsen, former Danish Medical Asociation president.

Here in Canada, legal changes to promote patient safety initiatives have

Box 1: Further reading

- Patient Safety, Medical Error and Tort Law: An International Comparison (www.osgoode.yorku.ca/faculty/Gilmour_Joan_M.html)

- Patient Safety Law: From Silos to Systems (www.patientsafetylaw.cal)

- Medical Liability Practices in Canada: Towards the Right Balance (www.cmpa-acpm.ca)

- Building a Safer System: A National Integrated Strategy for Improving Patient Safety in Canadian Health Care, (http://rcpsc.medical.org/publications /building_a_safer_system_e.pdf)

report on the operations of the pathology laboratory. Gilmour's report recommends that the continued existence of qualified privilege laws should be linked to evidence that requirements, to report error and disclose harm to patients, have been fulfilled.

Phil Hassen, chief executive officer of the Canadian Patient Safety Institute, says legal reform to improve safety needs to be addressed.

But Hassen quickly adds he's "not an expert in law and this is extraordinarily complex matter. I have really avoided the legal side of this."

Yet, legal considerations appear to be unavoidable, if not the foremost consideration in everyone's mind.

Even the use of some words (error, blame and harm) became a lightning rod when one of the Canadian Patient Safety Institute's multistakeholder working groups hammered out recently published national disclosure guidelines (CMAJ 
2007;177[11]:1342-3). The guidelines stated purposes are to promote "timely, truthful and transparent disclosure," assist patients in accessing further health care and personal supports and, at the same time, discourage attribution of blame. Yet, notably, a lengthy explanation of why the word "error" should be avoided takes a prominent place in the published document.

The guidelines "could have been more complete on the idea of apologies and compensation," says Dr. Rob Robson, chief patient safety officer at the Winnipeg Regional Health Authority.

Robson says that even in a tort-based system it is possible to formally provide compensation to patients without them having to start legal proceedings, pointing to the Veterans Affairs Medical Center in Lexington, Kentucky, where the hospital will approach patients who have suffered harm, acknowledge the error that led to the harm and initiate discussion about compensation.

Settlements with patients have increased, but the overall cost of payouts has fallen because of savings in legal costs, Robson says. The approach has since been adopted in many US jurisdictions.

The Winnipeg health region has developed a modest version of the process (Healthcare Quarterly 2008; 11 [Special Issue]). When patients are harmed by "something we are responsible for and could have done differently," they are offered an apology and the authority indicates its willingness to discuss compensation.

While Canadian hospitals and health systems do sometimes voluntarily offer compensation to patients, as far as Robson knows, "we're the only ones to develop a process to recognize cases like this, and make it explicit." The ultimate goal, he stresses, is to create conditions to understand what happened and reduce future risks.

To boost patient safety initiatives within Canada's existing legal context, Gilmour recommends in her report that the "substantial funding that governments contribute to the cost of physician and hospital liability coverage ... should be tied to improved performance in specified, targeted patient safety initiatives."

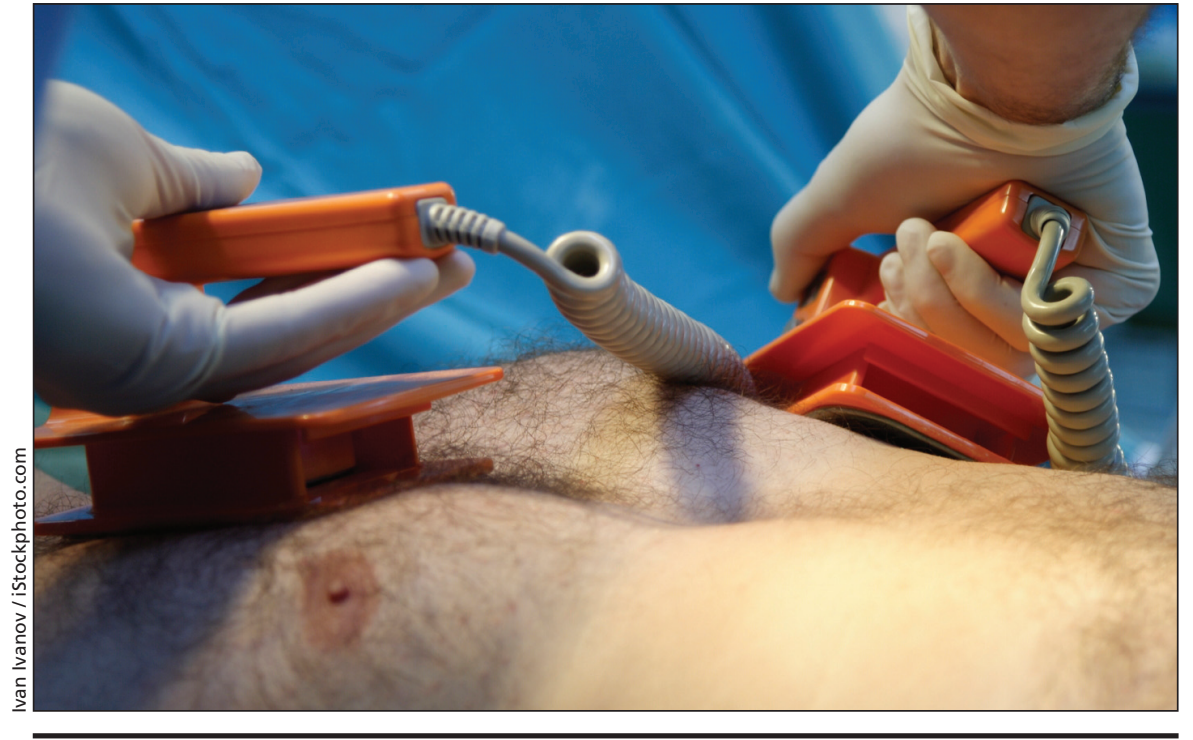

It has been estimated that $7.5 \%$ of patients admitted to Canadian hospitals suffer from 1 or more medical mishaps. The patient safety movement hopes that greater openness will lead to systemic reforms that will curb the number of errors.

Perhaps more controversially, she recommends that provinces consider legislation so that hospitals become liable for the negligence of nonemployed physicians who treat patients. The rationale for this is that institutions are better able to undertake systemic analysis, as well as make changes to reduce risk and prevent harm, than individual physicians, she argues.

Gilmour also says that education reform is in order. Health professionals "need to start thinking about mistakes that occur in a different way - they need to change their own self conception that the standard is one of perfection; that's not true of any of us. Errors will happen and we need to be able to find out about them and think about how to change both systems and people working in them to reduce the errors."

Vance Davis's mother, now co-chair of the fledgling organization Patients for Patient Safety Canada, knows the system failed her son. In the wake of his death she began thinking about no-fault compensation "like we have for auto [insurance] here in Saskatchewan."

Would the existence of such a system have made the hospital less guarded in its reaction to her concerns?

Donna Davis doesn't want any other family to lose a loved one the same way that she did.

So it was gratifying - in a bitter- sweet kind of way - to find out that 2 months after Vance's death, a case review prompted a directive to all Saskatchewan hospitals: when patients are transferred, sending and receiving nurses must do a full assessment together so noteworthy changes are recognized and can be acted on.

The Davises, however, were not invited to contribute to the case review and weren't told about the directive for months after it had been issued. It would be 6 years - and 1 day before the anniversary of Vance's death - before Donna and her husband Jack were invited to give their disclosure to the hospital about what they had observed in the last hours of their son's life.

A few days later, the Davises received a heartfelt, but belated, apology from the chief executive officer of the hospital where their son died. - Ann Silversides, CMAJ

DOI:10.1503/cmaj.081130

This is part 2 of a 3-part series exploring nofault insurance options (CMAJ 2008; 179[4]:309-11). Earlier articles examined complaints and compensation (CMAJ 2008; 178[1]:14-6, CMAJ 2008;178[6]:671-2 and CMAJ 2008;178[11]:1409-11).

In the next issue of CMAJ: No fault in Canada: experiments in the past and prospects for the future. 